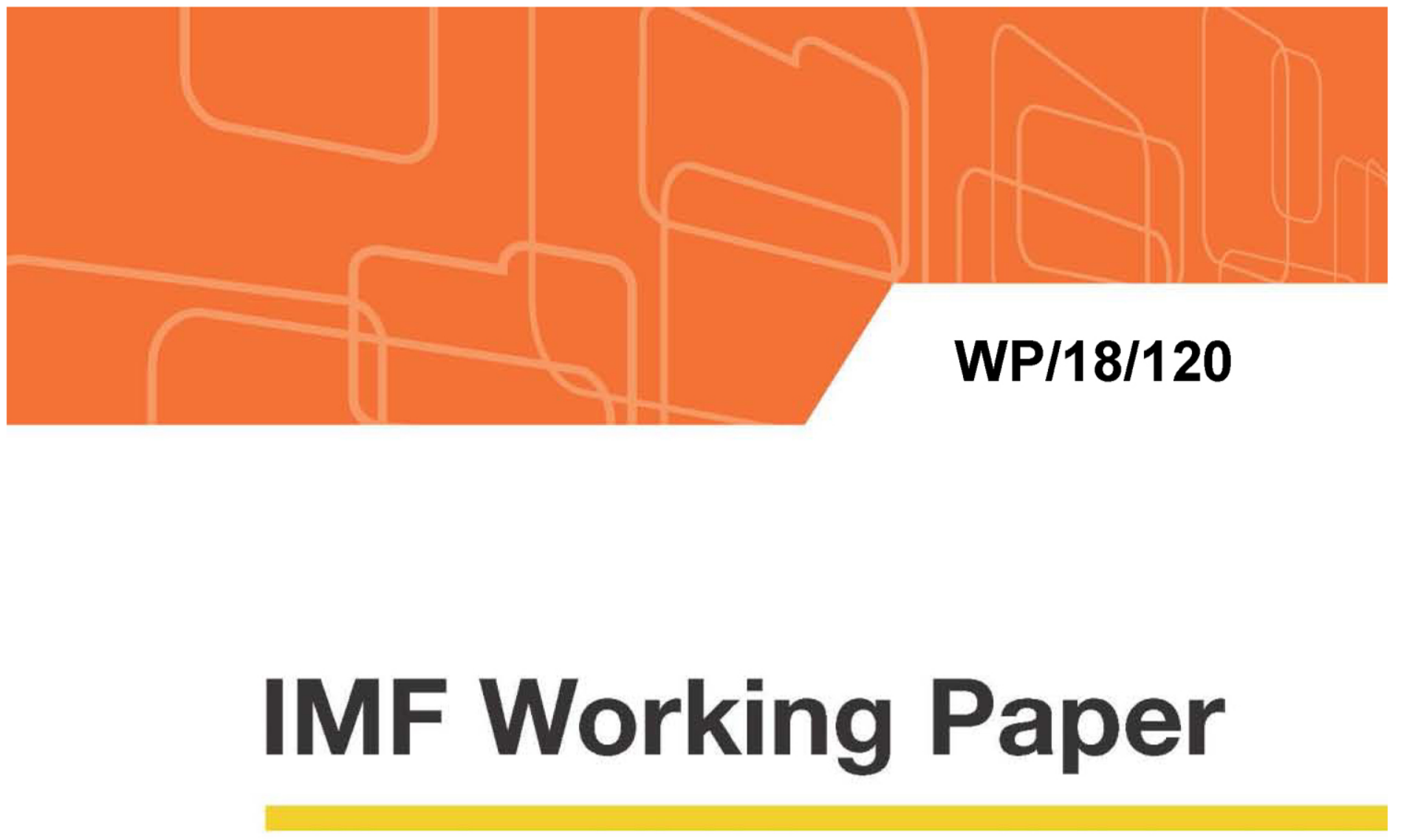

\title{
A Cohort-Based Analysis of Labor Force Participation for Advanced Economies
}

by Francisco Grigoli, Zsoka Koczan and Petia Topalova

IMF Working Papers describe research in progress by the author(s) and are published to elicit comments and to encourage debate. The views expressed in IMF Working Papers are those of the author(s) and do not necessarily represent the views of the IMF, its Executive Board, or IMF management.

I N T E R N A T I O N A L M O N E T A R Y F U N D 


\section{WP/18/120}

\section{IMF Working Paper}

\section{A Cohort-Based Analysis of Labor Force Participation for Advanced Economies}

by Francisco Grigoli, Zsoka Koczan and Petia Topalova

IMF Working Papers describe research in progress by the author(s) and are published to elicit comments and to encourage debate. The views expressed in IMF Working Papers are those of the author(s) and do not necessarily represent the views of the IMF, its Executive Board, or IMF management.
I N T E R
N A T I O N A L
$M O N E T A R Y$
F U N D 


\title{
A Cohort-Based Analysis of Labor Force Participation for Advanced Economies*
}

\author{
Francesco Grigoli ${ }^{\dagger} \quad$ Zsoka Koczan ${ }^{\ddagger} \quad$ Petia Topalova ${ }^{\S}$
}

\begin{abstract}
Advanced economies are in the midst of a major demographic transition, with the number of elderly rising precipitously relative to the working-age population. Yet, despite the acceleration in demographic shifts in the past decade, advanced economies experienced markedly different trajectories in overall labor force participation rates and the workforce attachment of men and women. Using a cohort-based model of labor force participation for 17 advanced economies estimated over the 1985-2016 period, we document a significant role of common patterns of participation over the life cycle and shifts in these patterns across generations for aggregate labor supply, especially in the case of women. The entry of new cohorts of women led to upward shifts in the age participation profile, boosting aggregate participation rates. However, this process plateaued in most advanced economies, with signs of reversal in some. Using the model's results to forecast future participation trends, we project sizable declines in aggregate participation rates over the next three decades due to the aging of the population. Illustrative simulations show that implementing policies encouraging labor supply can help attenuate but may not fully offset demographic pressures.
\end{abstract}

Keywords: Advanced economies, age, cohort, labor force participation, population aging, simulations.

JEL Codes: J01, J16, J21.

*The views expressed in this Working Paper are those of the authors and do not necessarily represent those of the IMF or IMF policy. Working Papers describe research in progress by the authors and are published to elicit comments and to encourage debate. We thank, without implicating, Stephanie Aaronson, Oya Celasun, Romain Duval, Davide Furceri, Gian Maria Milesi-Ferretti, and Maury Obstfeld for their comments and suggestions. Benjamin Hilgenstock, Christopher Johns, and Jungjin Lee provided excellent research assistance.

${ }^{\dagger}$ International Monetary Fund, Research Department, fgrigoli@imf.org.

¥International Monetary Fund, Research Department, zkoczan@imf.org.

§International Monetary Fund, Research Department, ptopalova@imf.org.

\section{CInternational Monetary Fund. Not for Redistribution}




\section{Contents}

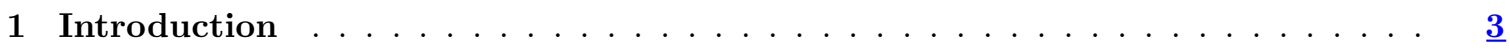

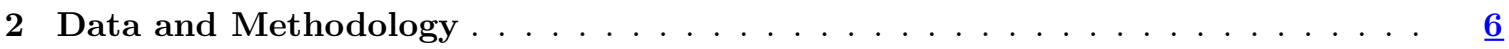

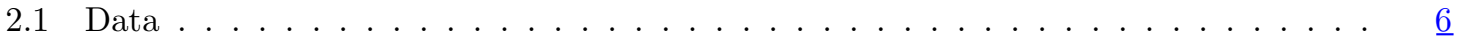

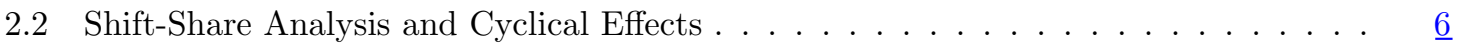

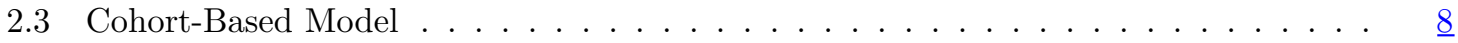

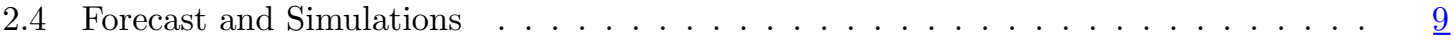

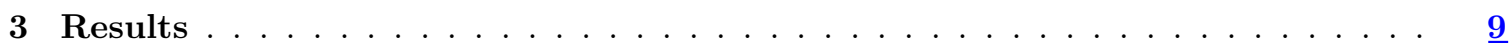

3.1 The Role of Aging and Cyclical Effects . . . . . . . . . . . . . . . $\underline{10}$

3.2 Age and Cohort Effects in Labor Force Participation Rates . . . . . . . . . . . $\underline{11}$

3.3 Illustrative Simulations . . . . . . . . . . . . . . . . . . . . . $\frac{12}{12}$

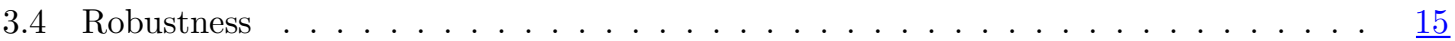

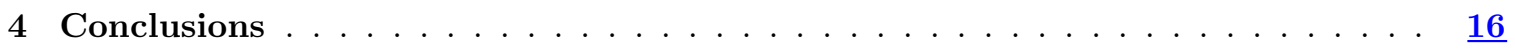

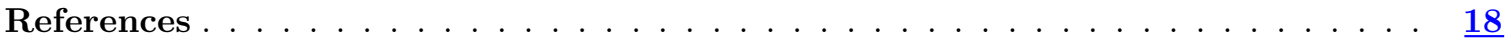

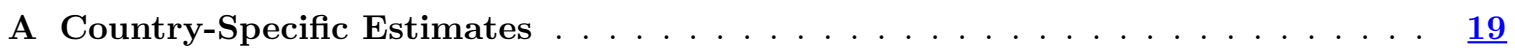

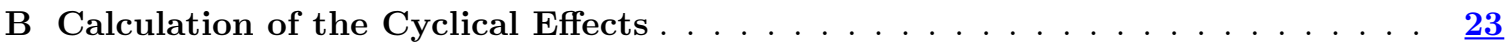

\section{List of Figures}

12. Page

1 Demographic Transition in AEs Compared to EMDEs . . . . . . . . . . . $\underline{3}$

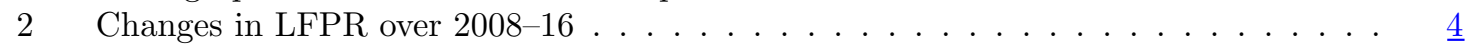

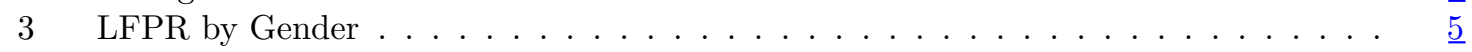

4 Changes in LFPR by Gender Since 2008: The Role of Aging and Cyclical Effects . . $\underline{10}$

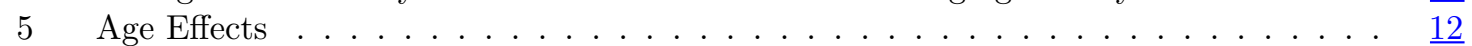

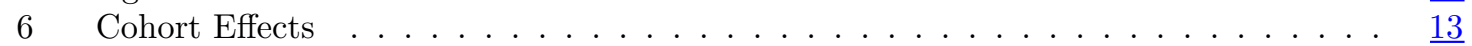

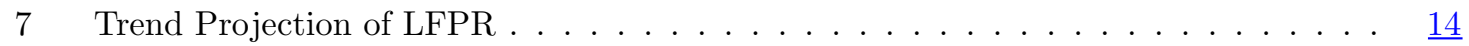

8 Changes in Trend LFPR Under Alternative Scenarios . . . . . . . . . . . . 15

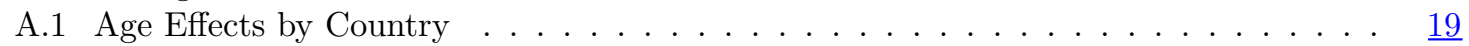

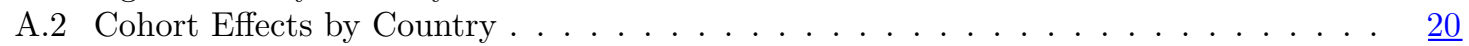

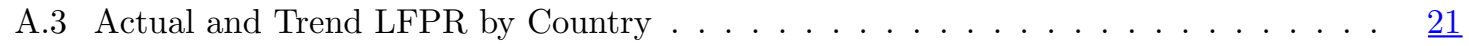

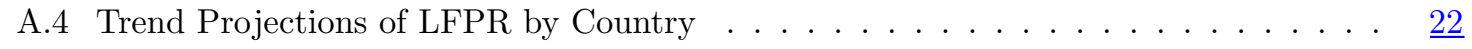

\section{List of Tables}

B.1 Regressions of Detrended LFPR . . . . . . . . . . . . . . . . Page 


\section{Introduction}

Advanced economies are in the midst of a major demographic transition. Population growth is slowing, life expectancy is rising, and the age structure is changing with the number of elderly rising precipitously relative to the working-age population. As shown in Figure 1, these trends are widespread across the advanced world and are expected to gather speed over the coming decades. The United Nations project that by the middle of this century, total population will be shrinking in almost half of advanced economies, and individuals of working age will support close to double the number of elderly they currently support.

Figure 1: Demographic Transition in AEs Compared to EMDEs
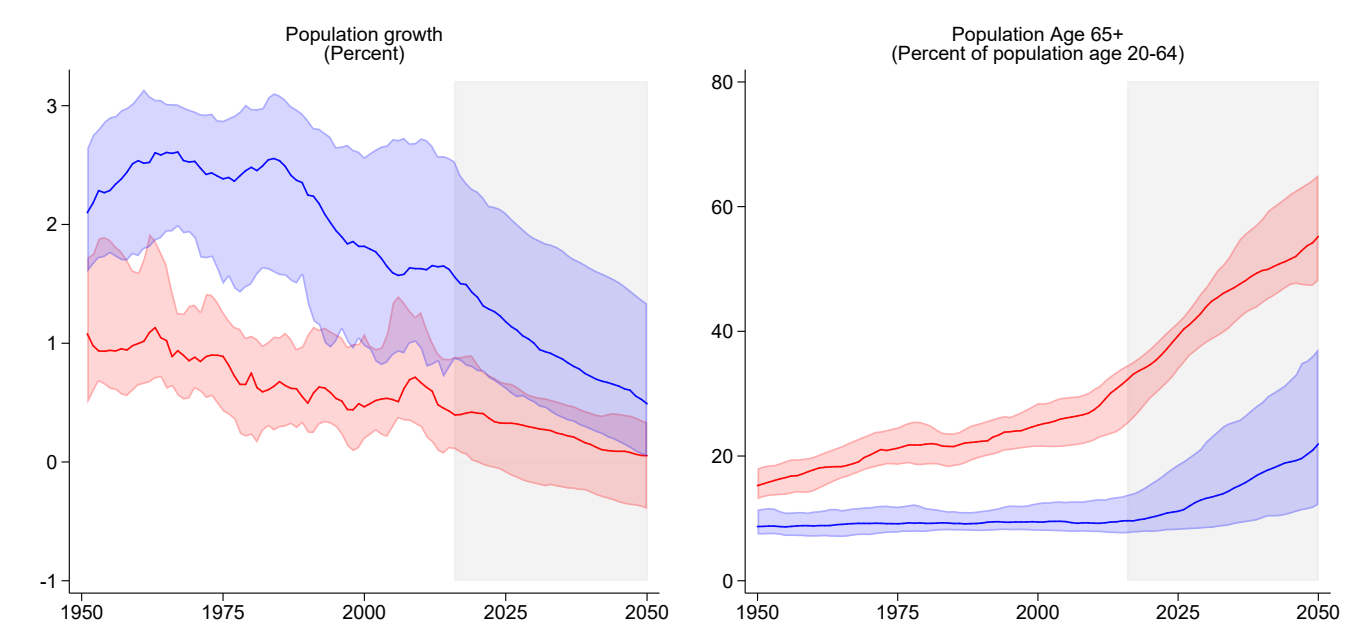

Source: Authors' calculations

Notes: Based on a sample of 36 AEs and 146 EMDEs. The red (blue) lines denotes the averages for AEs (EMDEs). Shaded red (blue) areas denote the interquartile ranges for AEs (EMDEs). Gray shaded areas indicate projections.

The aging of the population could weigh significantly on the supply of labor in advanced economies. Older workers tend to participate in the labor force at much lower rates than prime-age workers and unless participation rates among the rest of the population increase to offset these demographic trends, aging could have negative implications for advanced economies' potential growth and, in many cases, the sustainability of their social security systems (Clements et al., 2015). Increases in labor supply accounted for a significant share of advanced economies' potential growth in the 1985-2000 period; however, their contribution has fallen since (IMF, 2015).

Yet, despite the acceleration of the aging process in advanced economies over the past ten years, when the exceptionally large cohort of people born in the aftermath of World War II began reaching retirement ages, there is considerable heterogeneity in the evolution of aggregate labor force participation rates (LFPR) across countries. ${ }^{1}$ As shown in Figure 2, in about half of advanced economies, the LFPR increased since 2008. This pattern is surprising considering the deep and long-lasting recessions associated with the global financial and European debt crises and the marked acceleration of the demographic transition. Headline numbers also hide striking differences across the participation rates of different groups of workers. Figure 3 shows that aggregate male participation rates declined almost everywhere, while female participation rates increased in most coun-

\footnotetext{
${ }^{1}$ The LFPR is defined as the fraction of the adult population (ages 15 and over) either working or looking for work. In this paper, labor force participation and workforce attachment are used interchangeably.
} 
tries, both in the past decade and over a much longer time horizon.

Figure 2: Changes in LFPR over 2008-16

(Percent)
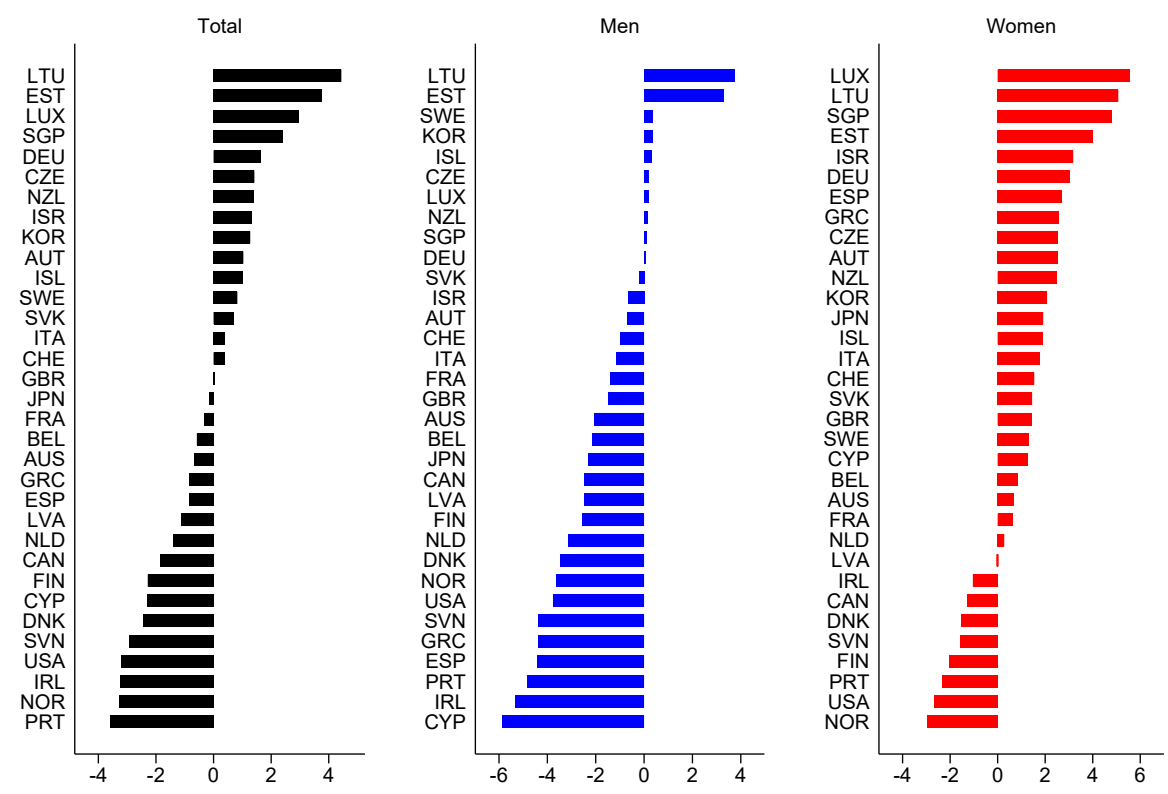

Source: Authors' calculations.

What underlies these divergent trends across countries and genders, and what are the prospects for labor force participation in advanced economies going forward? Differences in the exact timing and pace of the demographic transition as well as the severity of the impact of the global crisis on individual countries may explain some of the observed cross-country divergence. However, the striking disparity in participation trends across genders suggests a potentially important role for gender-specific cohort effects in shaping the long-term evolution of aggregate labor supply, with important implications for its future prospects. In particular, the gains in aggregate female LFPR over the past decades may reflect shifts in the propensity of different generations of women to work or seek employment, which may reflect changing social norms and preferences for participation (Fernández, 2013), and/or choices they may made early on in life, such as those related to education and fertility (Goldin, 2006).

In this paper, we shed light on these questions using several complementary empirical approaches. First, we quantify how much of the observed changes in aggregate LFPR across advanced economies in the past decade can be attributed to the acceleration in demographic shifts and cyclical effects, including the severe recessions associated with the global financial and European debt crises. To do so, we employ standard shift-share analysis to measure the contribution of changes in the age structure in advanced economies to participation trends for men and women separately. We capture the cyclical component of participation changes based on the historical relationship between detrended LFPR and output gaps. Second, we apply a cohort-based model to 17 advanced economies over the period 1985-2015 to generate the age participation profiles of men and women and analyze the role that birth cohorts played in shifting these profiles. We combine the findings of the cohort-based model with demographic projections to forecast the evolution of aggregate LFPR over the next three decades. Finally, we present the results from several illustrative sce- 

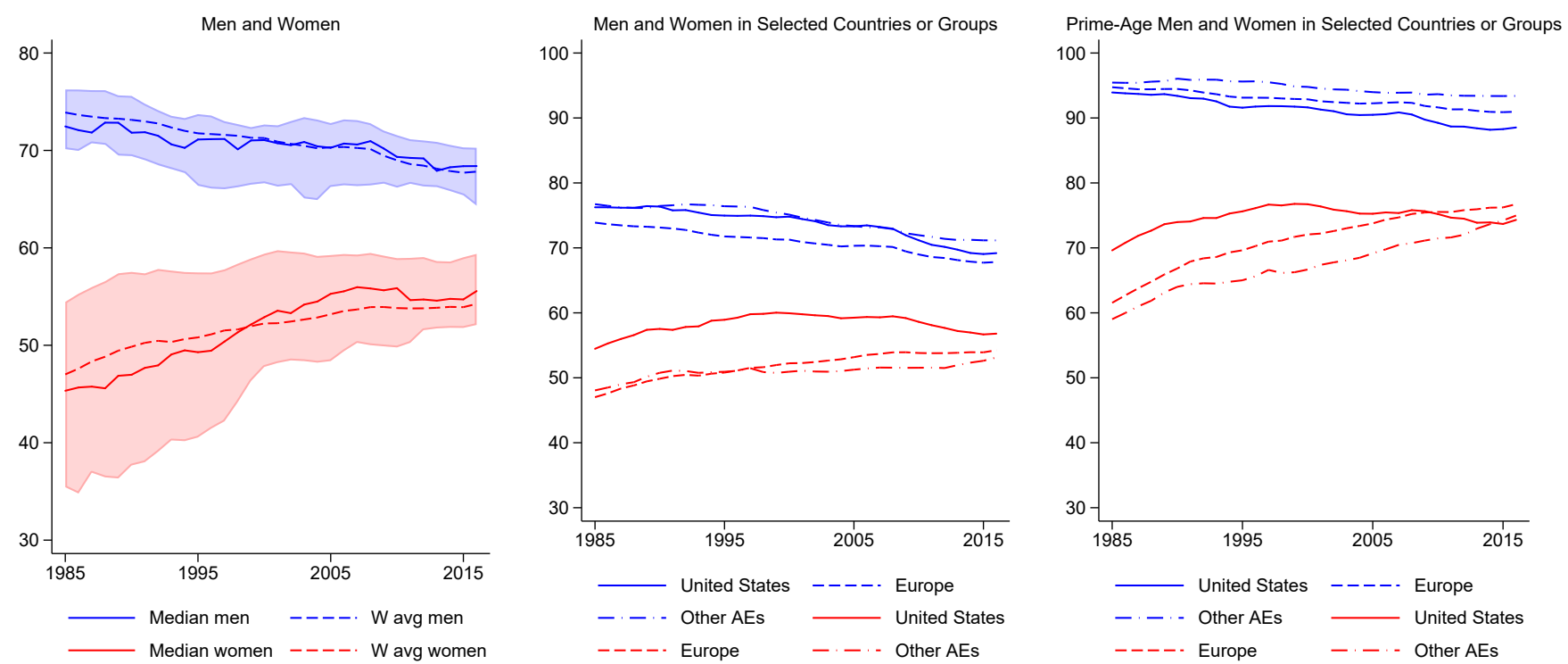

Source: Authors' calculations

Notes: Based on a sample of 33 AEs. Other AEs include Australia, Canada, Japan, and Korea. The dashed and dash-dotted lines for Europe and other AEs denote weighted averages. The Shaded areas denote the interquartile ranges.

narios of how these projections would vary based on the underlying assumptions about changes in age and gender effects, and labor market policies.

Our findings suggest that across advanced economies, on average, the changes in the labor force participation of men since 2008 are broadly consistent with the shifts in the age profile of the population and the drag from the global financial crisis. Women, on the other hand, despite aging, became significantly more likely to work or seek employment. The United States is an important exception to these patterns, with participation of both men and women falling more than what aging and the cycle would imply between 2008 and 2016. These findings are consistent with the results of the cohort-based model. In particular, newer cohorts of women are significantly more likely to work or seek employment, even though men are more likely to be part of the labor force than women during the prime-age years. The positive female cohort effects so far provided a sizable boost to the aggregate female LFPR counteracting the drags from aging and adverse cyclical conditions in many advanced economies. However, cohort effects plateaued recently and even edged down, a pattern which is especially pronounced in the United States. This finding suggests that the historical gains in female LFPR owing to the entry of new birth cohorts and the exit of older ones may no longer be an option for raising participation in many advanced economies.

Finally, illustrative simulations confirm that in the absence of policies to boost participation and assuming no further cohort effects, the trend participation rate would fall by about 5.5 percentage points on average over the next 30 years due to the projected population aging. This decline in participation could wipe out as much as 3 percent of potential economic output in the median advanced economy. Policies aimed at raising the participation of women and older workers are therefore needed to limit the fall in participation rates. 
Our paper contributes to several strands of literature. First, it quantifies the role of demographic shifts on labor force participation during a period of a marked acceleration in the aging process in most advanced economies. A number of papers used standard shift-share analysis to quantify the role of demographic changes in the population in labor force participation changes in the case of the United States (see, for example, Aaronson et al., 2014) and select advanced economies (IMF, 2017). Our contribution is to expand this analysis to 33 advanced economies for which detailed participation data are available and perform separate analyses for participation rates of men and women, which evolved along remarkably different trajectories over the past several decades. Second, the paper builds upon several studies that used cohort-based models of labor supply. Aaronson et al. (2006) and Fallick and Pingle (2007) first examine labor force participation in the United States through the lens of this empirical approach. Balleer et al. (2014) apply the methodology to six European countries, while Blagrave and Santoro (2017) use it in the case of Chile. Our paper extends the analysis to 17 advanced economies; to the best of our knowledge, this is the largest sample on which a cohort-based model was estimated. This exercise reveals important differences in the patterns of age and cohort effects across advanced economies. Finally, the paper uses the estimated age effects to forecast future participation trends in 17 economies and simulate the effects of labor market policy changes. This exercise builds on work by Burniaux and Jaumotte (2004) who use a similar approach to project labor supply in Organisation for Economic Co-operation and Development (OECD) economies under alternative policy options.

The rest of the paper is organized as follows. Section 2 describes the data used in the analysis and outlines the empirical methodology. Section 3 discusses the main findings and simulation scenarios. Section 4 concludes summarizing the key results and policy implications.

\section{Data and Methodology}

This section discusses the data used in the paper as well as the methodology to (i) decompose the change in LFPR into an aging component, a cyclical component, and a residual; (ii) estimate age and cohort effects in labor force participation; and (iii) forecast future participation trends and simulate illustrative scenarios.

\subsection{Data}

The series on labor force participation rates by gender and age-group used in the analysis come from the Employment database of the OECD. Although recent data are available for 33 advanced economies, sufficiently long historical series needed for the cohort-based analysis exist for a subset of 17 economies over the period 1985-2017. Other series used in the analysis, such as the output gap or the unemployment rate, are from the IMF World Economic Outlook Database. Population projections used in forecasting participation rates are from the 2017 edition of the United Nations World Population Prospects database.

\subsection{Shift-Share Analysis and Cyclical Effects}

To establish how much demographic shifts in the populations of advanced economies contributed to changes in LFPR since 2008, we perform a shift-share analysis separately for men and women 
in a sample of 33 advanced economies. ${ }^{2}$ This methodology decomposes observed changes in aggregate male and female LFPR since 2008 into changes in participation rates within each age group while holding population shares fixed ("within changes"), a shift in the relative sizes of age groups while holding participation rates fixed ("between changes"), and an interaction term. The role of aging can be approximated by the "between changes", which is the imputed change in participation if participation rates for each age group remained at their 2008 levels.

Formally, the gender-specific LFPR can be rewritten as the sum of the participation rates of workers of the same gender in different age groups, weighted by their share in the male or female population:

$$
l_{i, t}^{a}=\sum_{g=1}^{n} l_{i, t}^{a, g} \frac{\text { pop }_{i, t}^{a, g}}{\text { pop }_{i, t}}
$$

where $i$ denotes the country, $t$ is the time index, $a$ is the gender, $g$ is the quinquennial age group (starting at 15 years old up to 64 years old, and aggregated for those aged 65+), and pop is the population. We obtain the aging effect as the difference between the actual participation rate and the one computed by holding constant the gender- and group-specific participation rates at their 2008 level, $l_{i, 2008}^{a, g}$, but allowing the population shares, $\operatorname{pop}_{i, t}^{a, g} / p^{\prime} p_{i, t}$, to vary as observed in the data.

Economic contractions generally lead to higher unemployment and lower LFPR, as some workers get discouraged and permanently separate from the workforce, while others may choose to delay entry (Elsby et al., 2015). To separate out the effect of the cycle on LFPR, we estimate the following regression:

$$
l_{i, t}^{a, *}=\sum_{k=0}^{1} \beta^{k} O G_{i, t-k}+\pi_{i}+\tau_{t}+\epsilon_{i, t}
$$

where $l^{a, *}$ is the detrended LFPR of gender $a$, obtained by applying the Hodrick-Prescott (HP) filter to the LFPR; and $O G$ is the output gap. Country fixed effects, $\pi_{i}$, control for all time-invariant differences across countries, including differences in the average LFPR, while time fixed effects, $\tau_{t}$, capture all global shocks affecting the countries in the sample in a particular year.

Given the presence of cross-sectional dependence, we apply the Driscoll-Kraay correction of the standard errors. ${ }^{3}$ We estimate the regression using annual data from 1980-2016, separately for men and women, and calculate the cyclical effect at time $t$ as the predicted value of the regression. The difference in the predicted cyclical component relative to its 2008 value captures the role of the cycle in the change in aggregate LFPR since then. While the findings rely on a specification with a single lag estimated in a panel setting, the results are qualitatively similar if a richer lag structure is used instead, or the sensitivity of the labor force participation to the cycle is allowed to vary across countries. Results are also robust to employing the Corbae-Ouliaris filter instead of the HP filter to obtain the detrended aggregate labor force participation rate in equation (2). They are similarly robust to calculating detrended LFPR as a deviation from a three-year moving average, in order to limit the distortions generation by the endpoint problem in the HP filter.

\footnotetext{
${ }^{2}$ See Box 1.1 in IMF (2017) for a shift-share analysis of labor force participation for select advanced economies, and Aaronson et al. (2006) and CEA (2014) for an application to the United States.

${ }^{3}$ See Annex B for the results of the estimations.
} 


\subsection{Cohort-Based Model}

To capture the role of age and cohorts, we rely on country- and gender-specific cohort-based model estimations. Compared to the existing literature, we widen the focus of the analysis to all advanced economies for which we can obtain long enough series for annual data on LFPR for quinquennial age groups starting at 15 years old up to 64 years old, and aggregated for those aged over 65. This leaves us with a sample of 17 advanced economies over the period 1985-2016; to our knowledge, this is the largest sample on which a cohort-based model was estimated.

As discussed in Aaronson et al. (2006) and Fallick and Pingle (2007), this model assumes that people have a different propensity to work or seek employment over their life cycle (age effects), but each birth cohort (or generation) shares a common pattern of participation over their lifetime (cohort effects). For example, early in life, individuals are likely to be enrolled in education rather than working. Similarly, later in life, they tend to retire and permanently drop out of the labor force. Thus, we can calculate the propensity to participate in the labor force at any given age (i.e., the age effect) and the specific propensity of each cohort to participate in the labor force at any age (i.e., the cohort effect). For instance, a woman born in 1985 might be more likely to work at any given age than one born in 1945. Various factors can influence this propensity, including social norms, cultural attitudes, and preferences about working, as well as choices women within a certain cohort may make early in life about their educational attainment, fertility, and marriage. By controlling for cohort-specific effects, the model allows the identification of upward or downward shifts of the age participation profile depending on the birth year of the cohort. Variants of this approach have been adopted by Fallick and Pingle (ibid.), Aaronson et al. (2006), Aaronson et al. (2014) for the United States, Balleer et al. (2014) for select European countries, and Blagrave and Santoro (2017) for Chile.

More specifically, if $l_{t}^{a, g}$ is the LFPR for age group $g$, at time $t$, and gender $a$, it can be modeled as:

$$
l_{t}^{a, g}=\alpha^{a, g}+\frac{1}{n_{g}} \sum_{t-g}^{T} \beta^{a, g} C_{t-g}^{a}+\lambda^{a, g} X_{t}+\epsilon_{t}^{a, g}
$$

where $\alpha$ is a gender- and age-specific constant; $C$ is a set of birth cohort- and gender-specific dummy variables, which take the value of one if the birth cohort $t-g$ appears in the age group $g$ in year $t ;{ }^{4} \beta$ is a gender- and birth year-specific fixed effect, which is divided by the number of birth cohorts in the age group $n_{g} ;{ }^{5} X$ is the output gap; $\lambda$ is the coefficient on the output gap that varies by gender and age group; and $\epsilon$ is the error term.

We estimate equation (3) using a seemingly unrelated regression (SUR) approach simultaneously for 11 age groups, but separately for men and women in each of the 17 countries in the sample. Within each gender group and country, we constrain the coefficient for each birth cohort $\beta^{a, g}$ to be the same across equations. Also, we impose that each birth cohort appears in at least two equations. Since our sample covers the period 1985-2016, this implies that we can consider only the cohorts born between 1925 and 1994. Such condition is also instrumental to circumvent the issue of jumps in the estimated cohort effects for the cohorts that enter only one age group. ${ }^{6}$

\footnotetext{
${ }^{4}$ For example, in year 1985, the birth cohort dummy variable for those born between 1970 and 1974 takes value one for the equation of the age group 15 to 19 .

${ }^{5}$ In our estimations, $n_{g}$ is set to five for the quinquennial age groups, and to 34 for the age group $65+$.

${ }^{6}$ Balleer et al. (2014) and Aaronson et al. (2014) avoid the problem of jumps by estimating the model using single ages instead of age group, thereby reducing the changes in participation rates from one cohort to the next.
} 


\subsection{Forecast and Simulations}

To forecast future LFPR, we draw on the results of the cohort-based model and combine them with projected demographic changes from the United Nations. To do so, we first calculate the age group- and gender-specific trend LFPR, $l_{t}^{a, g, *}$, consistent with a closed output gap as:

$$
l_{t}^{a, g, *}=\hat{\alpha}^{a, g}+\frac{1}{n_{g}} \sum_{t-g}^{T} \hat{\beta}^{a, g} C_{t-g}^{a}
$$

We then aggregate the age group- and gender-specific trends using projected population shares to construct a baseline scenario though $2050:^{7,8}$

$$
l_{t}^{*}=\sum_{g}^{G} \sum_{a}^{A} l_{t}^{a, g, *} \sum_{g}^{G} \sum_{a}^{A} \operatorname{pop}_{t}^{a, g}
$$

As a last step, we smooth abrupt changes in the trend LFPR by taking its three-year moving average.

Finally, we construct illustrative scenarios by changing the assumptions on the age group- and gender-specific LFPR. In particular, we assume that LFPR of women converges to that of men $\left(l_{t}^{a, m, *}=l_{t}^{a, f, *}\right)$ over a 20-year horizon. We also assume that the LFPR of older workers converges to that of younger workers (e.g., $l_{t}^{60-64, g, *}=l_{t}^{55-59, g, *}$ ). To shed light on the potential role of polices in boosting future participation rates, we use the findings on the responsiveness of labor force participation to various labor market policies and settings estimated in Grigoli et al. (2018) and IMF (2018). We assume that policy settings converge to the "best possible" levels - defined as the $90^{\text {th }}$ (or $10^{\text {th }}$ ) percentile of the level observed among the larger sample of advanced economies used in Grigoli et al. (2018) and IMF (2018) and use the estimated elasticities to forecast future participation trends.

\section{Results}

In this section, we discuss the findings from the three empirical exercises in the paper (i) the quantification of the role of aging and cyclical effects in LFPR changes since 2008, (ii) the estimation of age and cohort effects across 17 advanced economies, and (iii) projections of LFPR through the middle of the century along with illustrative scenarios.

\footnotetext{
While this solution is preferable, data on five-year age groups is available for a larger set of countries.

${ }^{7}$ Since the data source for the LFPR is the OECD and population shares projections are from the United Nations, we splice the population shares from the OECD that are consistent with the LFPR with the population shares from the United Nations World Population Prospects. We use United Nations population projections, which assume medium fertility, and migration flows and policies in line with historical trends.

${ }^{8}$ Given the relatively long time horizon of the projections, we assume no effects from new cohorts entering the labor force.
} 


\subsection{The Role of Aging and Cyclical Effects}

Figure 4 shows the average role of aging and cyclical effects in LFPR changes since the demographic inflection point in 2008 across all advanced economies (left panels), Europe (mid left panels), the United States (mid right panels), and other advanced economies (i.e., Australia, Canada, and Japan) (right panels). The figures present our findings both for men (top panels) and women (bottom panels). As described in detail in Section 2.2, the role of aging is computed using simple shift-share analysis, the role of the cycle is estimated based on the historical relationship between LFPR and the output gap, and the unexplained portion is the difference between the actual changes in LFPR and the sum of aging and cyclical components. Simple averages are used to aggregate findings across countries.

Figure 4: Changes in LFPR by Gender Since 2008: The Role of Aging and Cyclical Effects

(Percent)
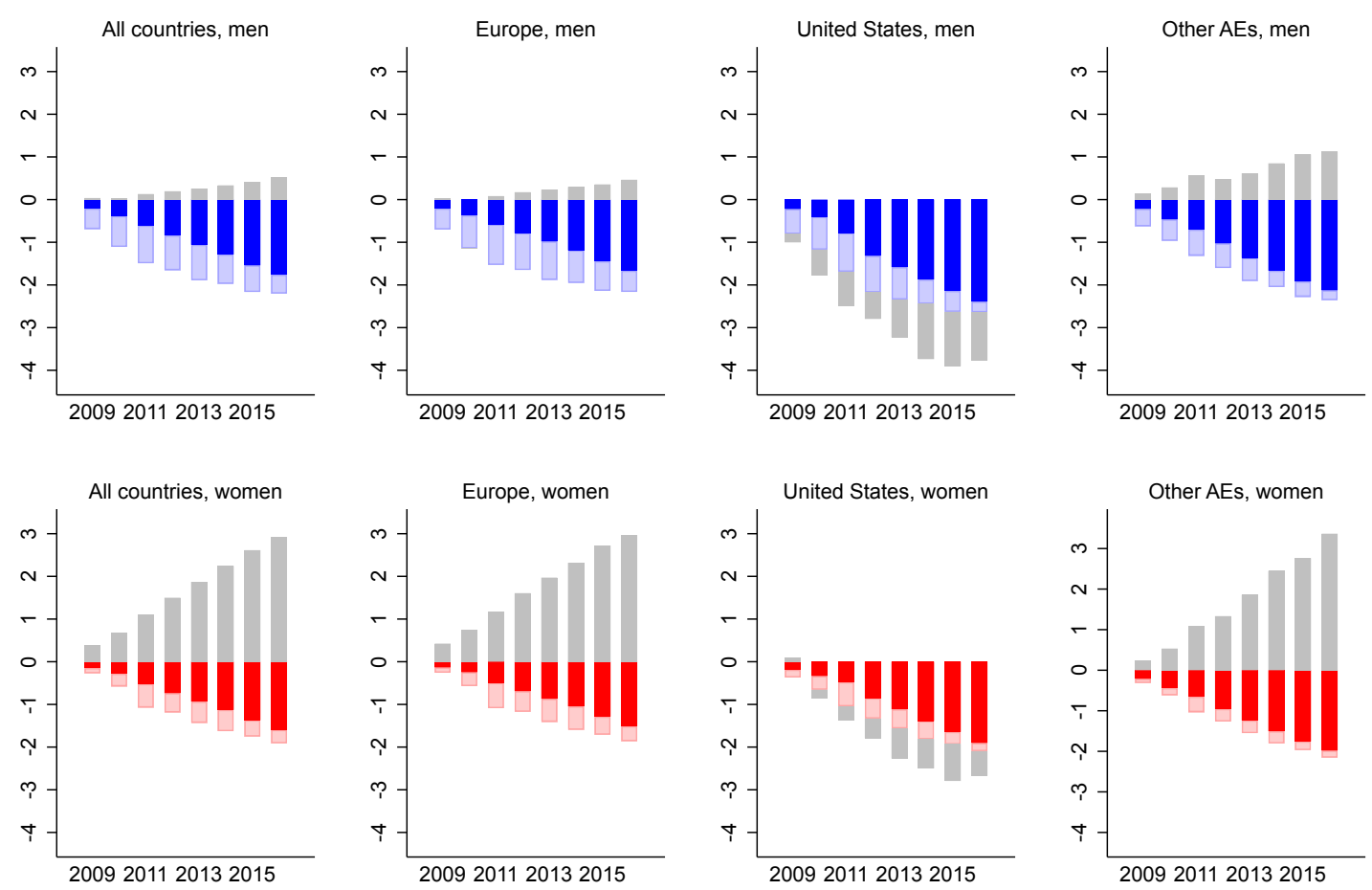

Source: Authors' calculations.

Notes: Based on a sample of 33 AEs. Blue (red) bars denote aging effects for men (women), light blue (light red) bars denote cyclical effect for men (women), and grey bars denote the residual.

As depicted in the leftmost column of Figure 4, our analysis suggests that, on average, the observed changes in participation of men are broadly consistent with the shifts in the population age profile since 2008 and the drag from the global financial and European debt crises. A very small share of changes in average male participation rates remain unexplained. Women, however, became significantly more likely to work or seek employment, despite aging and weak economic conditions, in the average advanced economy. For advanced economies, on average, there is a very sizable unexplained component in the observed changes in female participation rates. 
For both men and women, there are also notable differences across geographical regions. In the United States, participation of both men and women declined significantly more than aging and economic conditions would have predicted. In the average European and other advanced economy, on the other hand, gains in participation within demographic groups partially offset, and in some cases exceeded, the drag from aging. The role of cyclical developments is also evident. High unemployment and poor job prospects after the crisis depressed participation, especially in Europe and the United States. But as the recovery took hold, the drag from cyclical developments diminished considerably.

\subsection{Age and Cohort Effects in Labor Force Participation Rates}

Figure 5 and Figure 6 summarize the findings from estimating a cohort-based model of labor force participation for the 17 advanced economies, as described in detail in Section 2.3. Figure 5 plots the estimated age effects for the median and average country, the interquartile range of the countryspecific estimates, for the entire sample, as well as for specific groups of countries. ${ }^{9}$ The left panel shows a hump-shaped age-participation profile for men. Participation rates are close to 90 percent during the prime-age years (25-54), rising sharply during the early stages of life and declining dramatically after 55 . For women, the increase in the propensity to participate in labor markets during the late 20 s and early 30 s is less marked and participation levels remain substantially below those of men during the prime-age years. The shape of women's age participation profile is consistent with a larger share of women (relative to men) leaving the labor force to start a family in their late 20s and early 30s, and some of them rejoining the labor market in their $40 \mathrm{~s}$ and $50 \mathrm{~s}$. Another relevant feature of the age-participation profile of women is that the dispersion across countries is significantly wider than in the case of men. This is consistent with the much larger heterogeneity in the female LFPR in the countries considered as depicted in Figure $3 .^{10}$

Focusing on regional differences, the middle panel of Figure 5 shows that men in the United States tend to participate less than in Europe and other advanced economies during the prime-age years. However, European men join the labor force later than in the United States and drop out earlier. In other advanced economies, men tend to enter the labor force later than in the United States and, similar to European countries, participate at higher rates during the prime-age years. They are also significantly more likely to remain in the labor force later in life. The cross-country comparison of the age-participation profile of women in the right panel of Figure 5 reveals some interesting patterns as well. While in the United States women join the labor force earlier in life than in Europe, they drop out at a higher rate in their late 20s and early 30 s and continue to be inactive for longer.

The cohort effects displayed in Figure 6 present even more striking differences between men and women. ${ }^{11}$ As shown in the left panel, in the case of men, shifts in average participation rates due to the entry of new cohorts in the labor force are small. The estimated cohort effects fluctuate within a tight range around zero, becoming somewhat negative only for those born after $1975 .^{12}$ For women, each successive cohort starting with those born in 1940-44 until women born in 197579 contributed to an increase in the average LFPR. This pattern holds for virtually all countries in the sample, reflecting a broad-based evolution of preferences and social norms. For example,

\footnotetext{
${ }^{9}$ Regression results for each country and gender are not reported in the interest of space, but are available upon request. Figure A.1 of appendix A contains country-specific estimates of age effects of all countries in the sample.

${ }^{10}$ The standard deviation of age effects for prime-age women is 3 to 6 percentage points higher than for men.

${ }^{11}$ See Figure A.2 of appendix A for the country-specific estimates of cohort effects of all countries in the sample.

${ }^{12}$ For the majority of the countries in the sample, we cannot reject the null hypothesis that the cohort effects are different from zero before 1975 .
} 

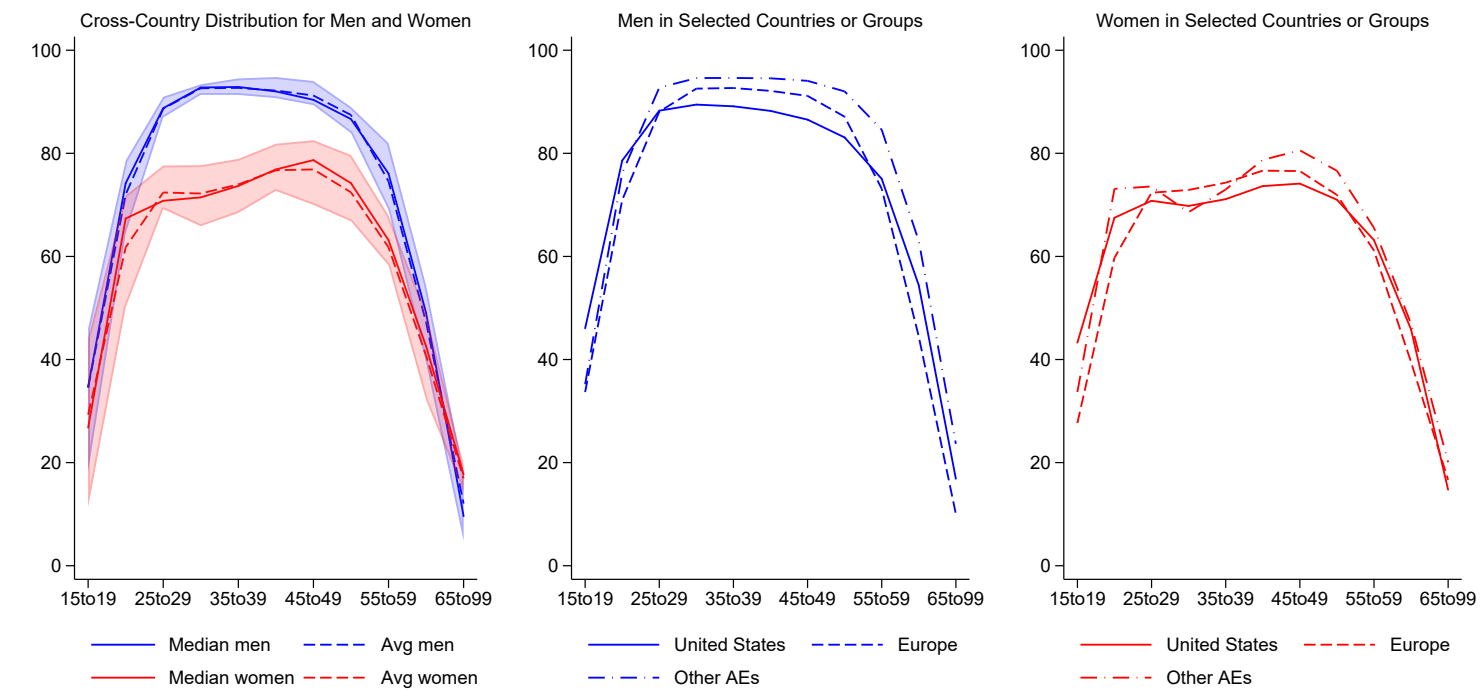

Source: Authors' calculations.

Notes: Based on a sample of 17 AEs. Other AEs include Australia, Canada, and Japan. Shaded areas denote interquartile ranges.

in the median country, the LFPR of women born in the 1970s is up to 4 percentage points higher than the LFPR of women born in the early 1930s. Importantly, however, cohort effects plateaued since 1980 and even started to edge down more recently. This suggests that further gains in the aggregate female labor force participation rates from the entry of new cohorts of women in the labor force may be limited for the median advanced economy.

The middle panel of Figure 6 reveals that earlier cohorts shifted the age-participation profile of men upwards in the United States, while positive contributions are smaller for Europe and other advanced economies. Recent cohorts, however, reversed some of the gains, especially in the United States. For women, there is also interesting regional variation in the estimated cohort effects as depicted in the right panel of Figure 6. In the United States (and in some European countries such as Denmark and Sweden), the cohort effects for women plateaued earlier and, in the case of the United States, significantly declined. This is consistent with the stylized facts. The United States enjoyed higher levels of female LFPR in the 1980s and 1990s relative to most other advanced economies. However, its lead has eroded due to the large increases in the workforce attachment of women in other parts of the advanced world in recent years (Figure ??).

\subsection{Illustrative Simulations}

Based on the results of the cohort-based model, we forecast trend LFPR through 2050 and construct some illustrative scenarios of how LFPR may evolve over the next 30 years. As a starting point, Figure 7 displays the actual and trend LFPR. Starting in the second half of the 1980s, the median trend LFPR across the sample of 17 advanced economies increased by 5.5 percentage points, reaching 62 percent in 2012. Since then, it started to decline to about 60 percent in 

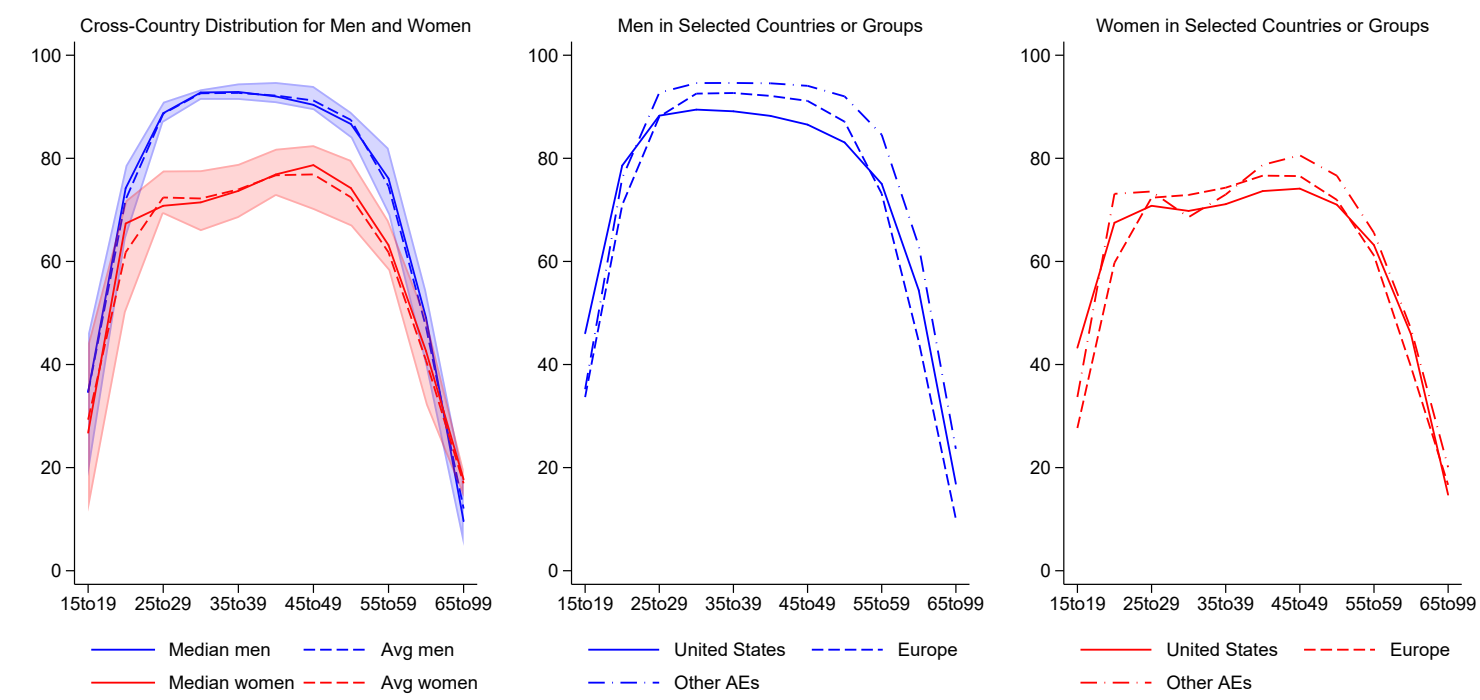

Source: Authors' calculations.

Notes: Based on a sample of 17 AEs. Other AEs include Australia, Canada, and Japan. Shaded areas denote interquartile ranges.

2016. Importantly, while the dispersion in trend participation rates at the beginning of the sample is quite large, it shrinks considerably during the last ten years reflecting the decline in the heterogeneity in female LFPR across countries. ${ }^{13}$ After 2016, we display the projected trend LFPR under the Baseline scenario, which assumes no changes to policies that may affect participation decisions of men and women. As discussed in Section 2.4, the projection is made under the assumption that the output gap is closed, and new cohorts entering the labor market do not shift the age participation profile. Thus, the only factor affecting the evolution of aggregate participation rates are the projected shifts in the population across age buckets. This exercise suggests that in the median country, trend LFPR could fall significantly, reaching 54.5 percent in 2050 . As shown by the interquartile range, such decline would be broad-based, with several countries experiencing very sizable declines. All else constant, a decline in aggregate participation of 5.5 percentage points would translate into a 3 percentage point reduction in potential output by 2050 for the typical advanced economy. ${ }^{14}$

We develop three alternative scenarios. Figure 8 displays the changes in trend labor force participation that would occur under the alternative scenarios and compares it with the baseline discussed above. ${ }^{15}$ The first alternative scenario - which we call the Closing Gender Gaps scenarioassumes that prime-age women's participation rates will converge to those of prime-age men over

\footnotetext{
${ }^{13}$ See Figure A.3 of appendix A for the country-specific estimates of trend LFPR for all countries in the sample.

${ }^{14}$ For the purpose of this exercise, the labor share of income is assumed to be 56 percent, which corresponds to the average labor share of income in 2017 for a subset of advanced economies (Australia, Canada, Germany, Italy, Japan, Spain, and the United States). The fall in potential output is thus obtained by multiplying the average labor share of income by the projected fall in labor force participation during 2017-50. If this were to occur at the same rate every year, it would correspond to a loss in potential output of 0.09 percentage point a year over 33 years.

${ }^{15}$ See Figure A.4 of appendix A for the country-specific estimates of trend LFPR under the alternative scenarios for all countries in the sample.
} 
Figure 7: Trend Projection of LFPR

(Percent)

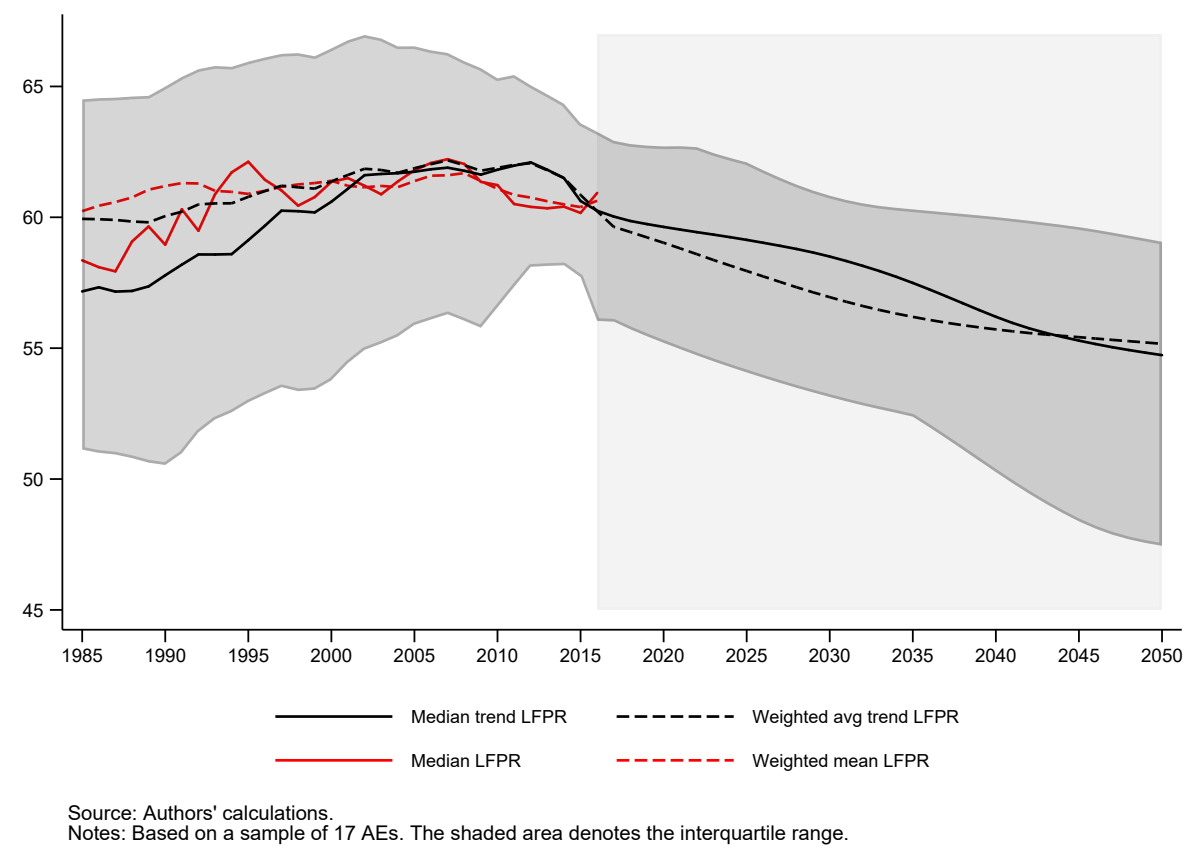

the next 20 years in a linear fashion. Thereafter, participation rates will remain constant. As shown in the left panel of Figure 8, this assumption would help contain the demographic pressures on the aggregate LFPR, but would not be sufficient to offset them. By 2050, the median trend LFPR would be only 2.6 percentage points higher than in the baseline scenario.

The second alternative scenario - the Extending Working Lives scenario-assumes that older workers drop out of the labor force later in life than they currently do. Specifically, the trend LFPR of those in the age group 55 to 59 would converge to that of the age group 50 to 54 over 20 years, and the trend LFPR of those in the age group 60 to 64 would converge to that of the age group 50-54 over the next 40 years. This would make the decline in the median trend LFPR more gradual and in 2050 it would be 2.7 percentage points higher than in the baseline scenario.

Finally, we simulate a third scenario - called Implementation of Policies scenario-that features a broad-based implementation of policies that the literature finds supportive of labor force participation. Drawing on the estimation results of Grigoli et al. (2018) and IMF (2018), we assume that every country adjusts its policy settings to the "best possible" levels - defined as the $90^{\text {th }}$ (or $10^{\text {th }}$ ) percentile of the level observed in the sample - over the next 20 years. ${ }^{16}$ This scenario, similar to the scenarios discussed above, is illustrative in nature. It would be very difficult for a country to change all these policies at the same time, given the sizable fiscal cost some of these may entail. Moreover, hard-to-predict non-linearities in the response of LFPR, due to, for example in-

\footnotetext{
${ }^{16}$ The policy changes considered are the following: increasing spending on active labor market programs, raising public spending on child care and early childhood education, extending job-protected maternity leave, lifting constraints on part-time work, increasing the statutory retirement age, reducing the tax wedge and the generosity of unemployment benefits, implementing migration-friendly policies, and reducing spending on incapacity and old-age pensions. See Grigoli et al. (2018) and IMF (2018) for a discussion of the expected effects of these policies.
} 
teractions of policies, may dramatically alter their outcomes. Notwithstanding these issues, the scenario is informative of the extent to which policies could help counteract the effects of aging. As shown in the right panel of Figure 8, policy implementation could reduce aging pressures and by 2050 , the median trend LFPR would be 1.2 percentage points higher than in the baseline scenario. ${ }^{17}$

Figure 8: Changes in Trend LFPR Under Alternative Scenarios

(Percent)
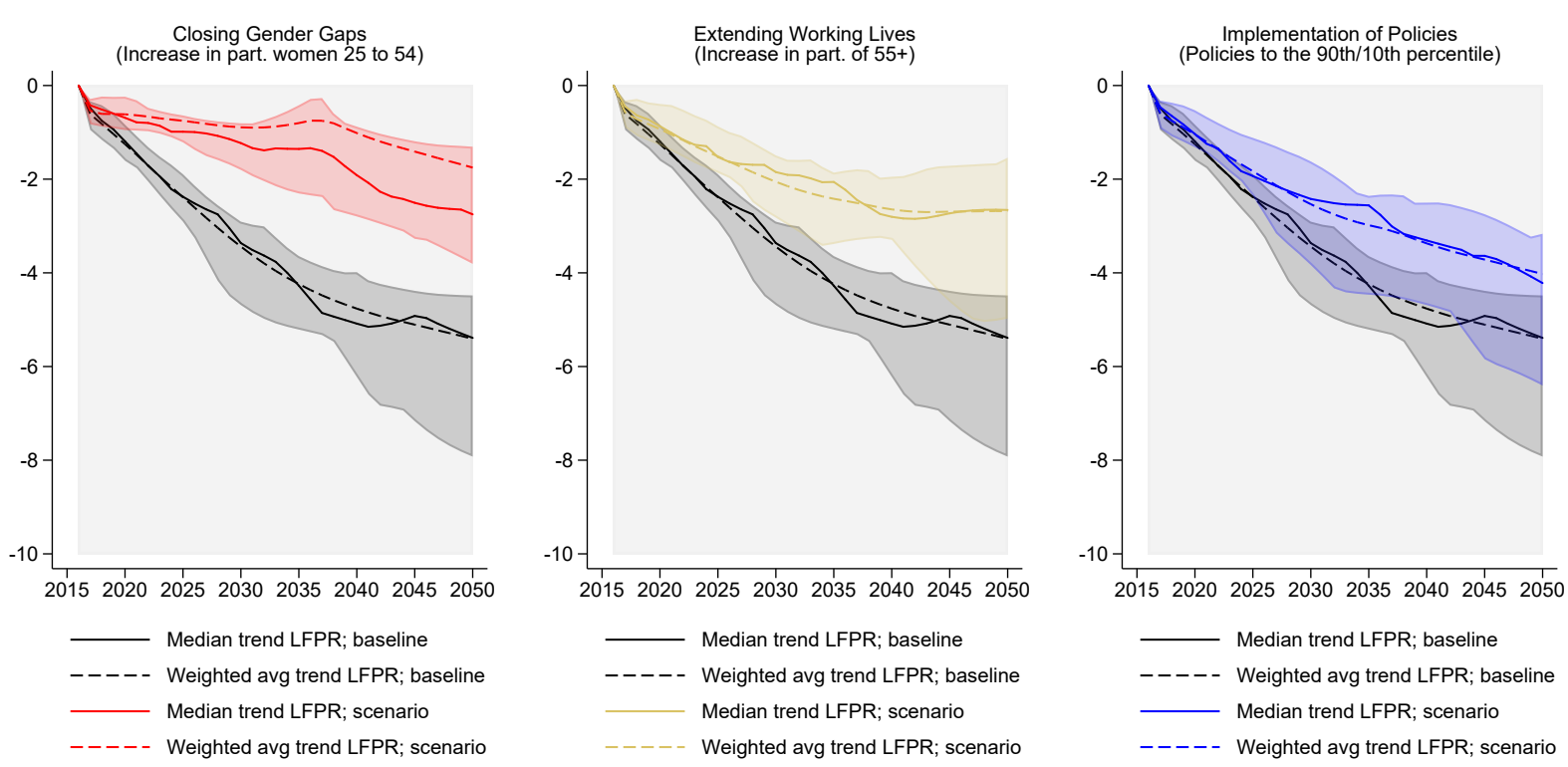

Source: Authors' calculations.

Notes: Based on a sample of $17 \mathrm{AEs}$. Shaded areas denote interquartile ranges.

\subsection{Robustness}

We perform a series of tests to ensure that our findings are robust. In the case of the cyclical effects calculation, we first modify equation (2) by adding more lags. Second, we replace the output gap with the unemployment gap, defined as the gap between current unemployment and the non-accelerating inflation rate of unemployment, NAIRU); and we augment the specification with a dummy variable that takes value one when a currency crisis, a sudden stop, a debt crisis, or a banking crisis occurs, based on Gourinchas and Obstfeld (2012), as well as with an interaction term between the unemployment gap and the dummy variable. ${ }^{18}$ Third, we estimate the same equation allowing the sensitivity of LFPR to the cycle to vary across countries, instead of estimating it in a panel setting. Fourth, we add the squared term of the output gap or the unemployment gap. We also estimate the same equation in first differences. And finally, we employ the filter in

\footnotetext{
${ }^{17}$ An additional scenario featuring a convergence of educational attainment to the "best possible" levels-defined as the $90^{\text {th }}$ percentile of the level observed in the sample-over the next 20 years returns a path for the median trend LFPR very similar to the baseline scenario. This reflects positive contributions for prime-age men and women and older workers that offset the negative contributions for the young, which would need to stay in school longer.

${ }^{18}$ See IMF (2013) for a discussion of the construction of the NAIRU.
} 
Corbae and Ouliaris (2006) instead of the HP filter to obtain the detrended aggregate labor force participation rate, or, alternatively, we calculate the latter as the deviation from a three-year moving average. ${ }^{19}$ We obtain qualitatively similar results under all these alternative specifications.

With respect to the cohort analysis, we first run the analysis using the logistic transformation of the LFPR. Similar to Balleer et al. (2014) and Aaronson et al. (2014), we apply the logistic transformation to the LFPR to account for the fact that rates are bounded between 0 and 100. Also, we run the analysis using a log transformation as in Fallick and Pingle (2007) and Blagrave and Santoro (2017). Second, we replace the output gap with, alternatively, the unemployment rate and the unemployment gap. The latter is defined as the gap between current unemployment and the non-accelerating inflation rate of unemployment. Again, results remain largely unchanged. Third, we drop more birth cohorts at the end of the sample. Specifically, we impose that every birth cohort is observed at least in three or four age groups. This implies dropping those born during 1985-89 and those born during 1980-84. The results remain largely unchanged.

\section{Conclusions}

The increase in longevity is one of the most remarkable successes in human history (Bloom et al., 2015). Yet, coupled with the decline in population growth rates, it could have important macroeconomic consequences. As older workers tend to participate in the labor force at much lower rates, population aging raises concerns about the supply of labor in advanced economies with implications for potential growth and the sustainability of social insurance systems.

This paper documents that, despite the acceleration in population aging over the past decade, many advanced economies have been successful in counteracting its downward pressure on labor force participation. In about half of advanced economies, the aggregate labor force participation rate increased after the global financial crisis. Yet, these aggregate developments mask strikingly different shifts in the workforce attachment of men and women. In most countries, the aggregate participation rates of men declined over this period, broadly in line with the changes in the age structure of populations. Aging can explain almost the entire change in male participation since 2008 in advanced Europe, and around 70 percent of the especially pronounced decline in the United States. Women's participation, on the other hand, increased in most countries, despite aging and the drag from the crisis, with the United States being an important outlier.

These findings are consistent with the results of the cohort-based model of labor force participation. According to the model, shifts in average participation rates due to the entry of new cohorts of men are very small. Conversely, in the case of women, newer cohorts contributed very substantively to gains in average LFPR across almost all countries in the sample, reflecting a broad-based evolution of preferences and social norms. The positive female cohort effects, however, plateaued since the cohort born in 1980 and even started to edge down more recently, especially in the United States. This finding suggest that further gains from higher labor force participation of new cohorts of women are likely to be limited.

Finally, the paper shows that by 2050 the LFPR could fall by over 5 percentage points for the median advanced economy in the absence of policies to boost participation. Illustrative simulations suggest that even if countries converge to the best (observed) policy settings from the point of view of encouraging labor supply, expected demographic shifts may still depress participation

\footnotetext{
${ }^{19}$ The Corbae-Ouliaris filter and the deviation from the three-year moving average of the LFPR should limit the distortions generated by the endpoint problem of the HP filter.
} 
rates. Thus, unless technological progress delivers offsetting productivity gains, many countries may need to reconsider immigration policies to boost domestic labor supply, alongside policies to encourage older workers to postpone retirement. 


\section{References}

Aaronson, Stephanie, Tomaz Cajner, Bruce Fallick, Felix Galbis-Reig, Christopher Smith, and William Wascher (2014). "Labor Force Participation: Recent Developments and Future Prospects". In: Brookings Papers on Economic Activity 2014.2, pp. 197-275.

Aaronson, Stephanie, Bruce Fallick, Andrew Figura, Jonathan F Pingle, and William L Wascher (2006). "The Recent Decline in the Labor Force Participation Rate and its Implications for Potential Labor Supply". In: Brookings Papers on Economic Activity 2006.1, pp. 69-154.

Balleer, Almut, Ramon Gomez-Salvador, and Jarkko Turunen (2014). "Labour force participation across Europe: a cohort-based analysis". In: Empirical Economics 46.4, pp. 1385-1415.

Blagrave, Patrick and Marika Santoro (2017). "Labor Force Participation in Chile: Recent Trends, Drivers, and Prospects". In: International Monetary Fund Working Paper 17/54.

Bloom, David E, Somnath Chatterji, Paul Kowal, Peter Lloyd-Sherlock, Martin McKee, Bernd Rechel, Larry Rosenberg, and James P Smith (2015). "Macroeconomic Implications of Population Ageing and Selected Policy Responses". In: The Lancet 385.9968, pp. 649-657.

Burniaux Jean-Marc, Romain Duval and Florence Jaumotte (2004). "Coping with Ageing: A Dynamic Approach to Quantify the Impact of Alternative Policy Options on Future Labour Supply in OECD Countries". In: OECD Working Paper ECO/WKP(2003)5.

CEA (2014). "The Labor Force Participation Rate Since 2007: Causes and Policy Implications". In: Council of Economic Advisers, Executive Office of the President of the United States.

Clements, Benedict J, Kamil Dybczak, Vitor Gaspar, Sanjeev Gupta, and Mauricio Soto (2015). "The Fiscal Consequences of Shrinking Populations". In: Staff Discussion Note, 15/21, International Monetary Fund.

Corbae, Dean and Sam Ouliaris (2006). "Extracting Cycles from Nonstationary Data". In: Econometric Theory and Practice: Frontiers of Analysis and Applied Research, pp. 167-77.

Elsby, Michael WL, Bart Hobijn, and Ayşegül Şahin (2015). "On the Importance of the Participation Margin for Labor Market Fluctuations". In: Journal of Monetary Economics 72, pp. 6482.

Fallick, Bruce and Jonathan F Pingle (2007). "A Cohort-Based Model of Labor Force Participation". In: FEDS Working Paper No. 2007-09.

Fernández, Raquel (2013). "Cultural Change as Learning: The Evolution of Female Labor Force Participation over a Century". In: American Economic Review 103.1, pp. 472-500.

Goldin, Claudia (2006). "The Quiet Revolution that Transformed Women's Employment, Education, and Family". In: American Economic Review 96.2, pp. 1-21.

Gourinchas, Pierre-Olivier and Maurice Obstfeld (2012). "Stories of the Twentieth Century for the Twenty-First". In: American Economic Journal: Macroeconomics 4.1, pp. 226-65.

Grigoli, Francesco, Zsoka Koczan, and Petia Topalova (2018). "Drivers of Labor Force Participation in Advanced Economies". In: International Monetary Fund Working Paper, forthcoming.

IMF (2013). "The Dog That Didn't Bark: Has Inflation Been Muzzled or Was It Just Sleeping?" In: World Economic Outlook, Chapter 3, International Monetary Fund.

- (2015). "Uneven Growth: Short and Long-term Factors". In: World Economic Outlook, Chapter 3, International Monetary Fund.

- (2017). "Seeking Sustainable Growth: Short-Term Recovery, Long-Term Challenges". In: World Economic Outlook, Chapter 1, October, International Monetary Fund.

- (2018). "Labor Force Participation in Advanced Economies: Drivers and Prospects". In: World Economic Outlook, Chapter 2, International Monetary Fund. 


\section{Appendix A. Country-Specific Estimates}

Figure A.1: Age Effects by Country

(Percent)
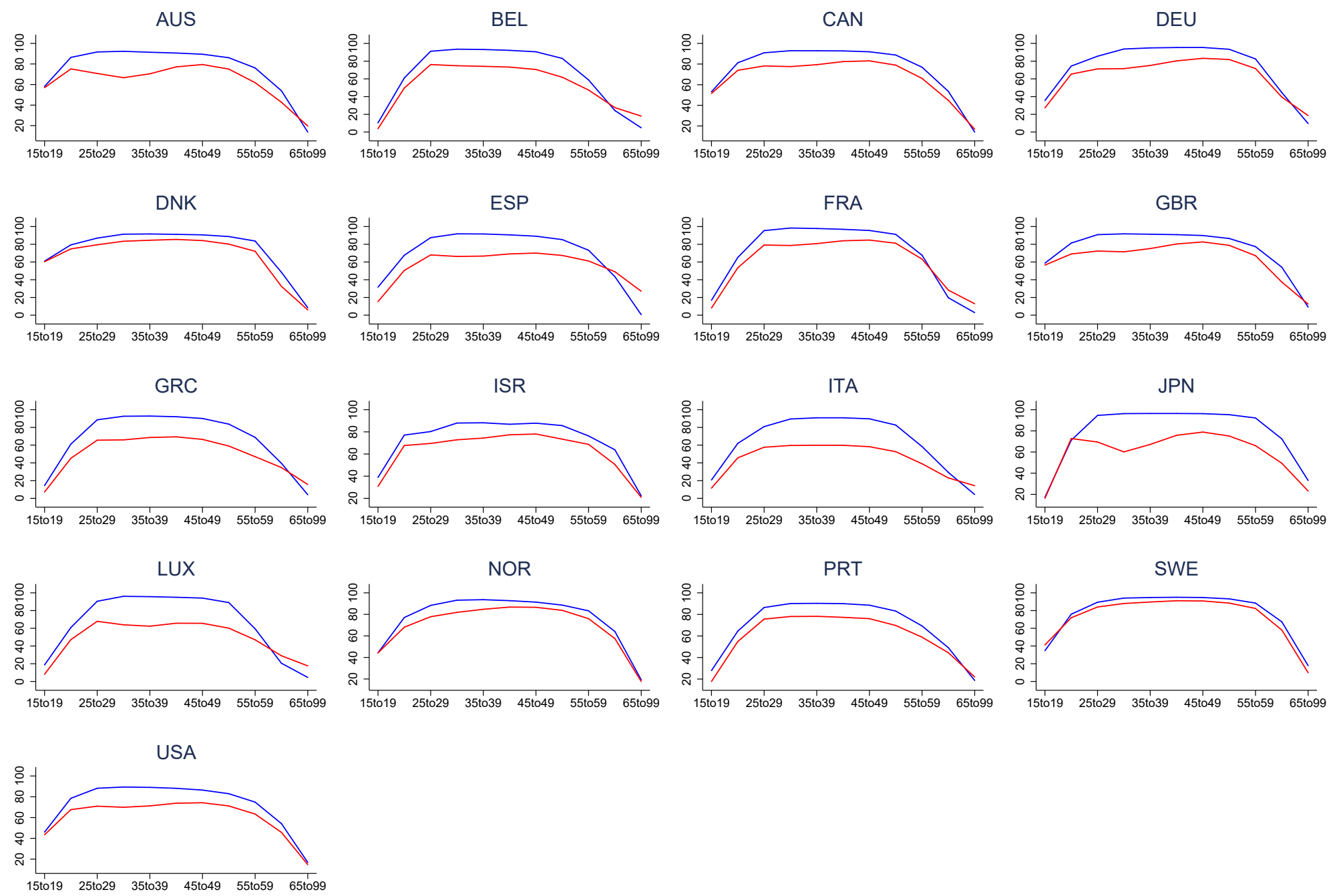

Source: Authors' calculations.

Notes: The red and blue lines denote the men and women age effects, respectively. 
Figure A.2: Cohort Effects by Country

(Percent)

AUS

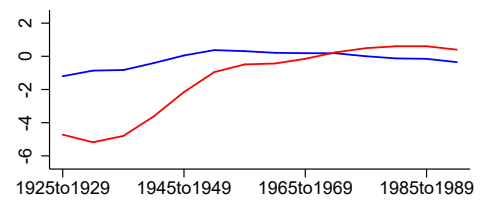

DNK

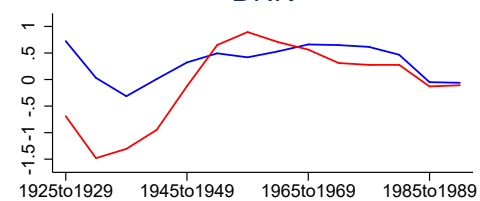

GRC

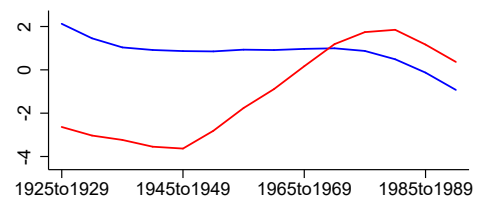

LUX

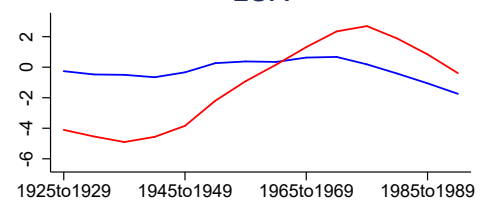

USA

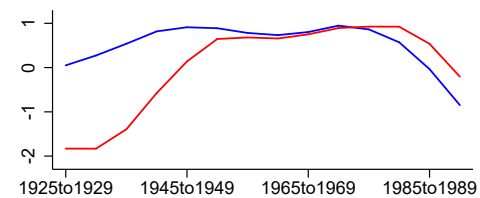

Source: Authors' calculations.

Notes: The red and blue lines denote the men and women age effects, respectively
BEL

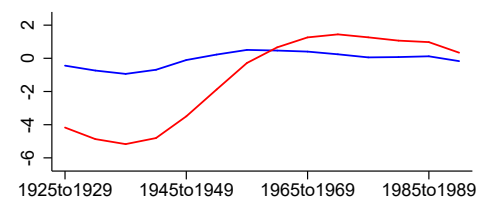

ESP

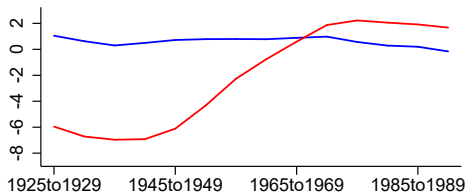

ISR

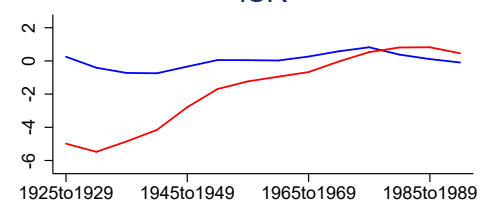

NOR

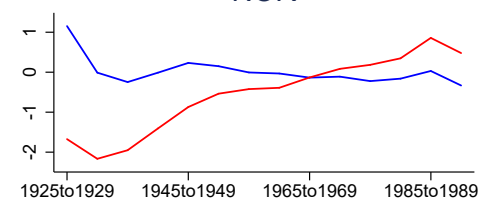

CAN

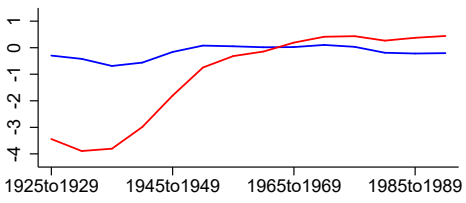

FRA

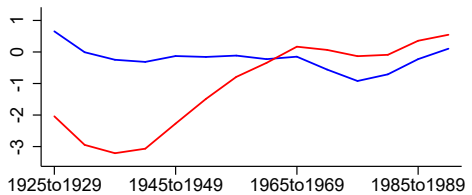

ITA

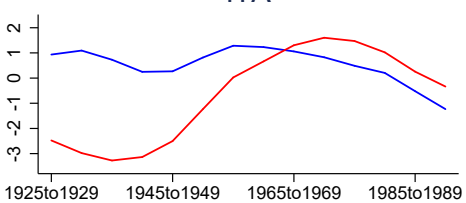

PRT

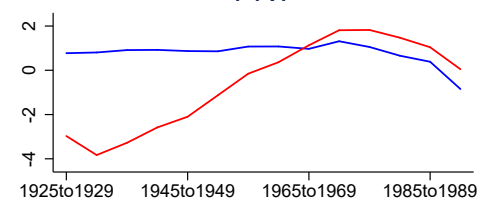

DEU

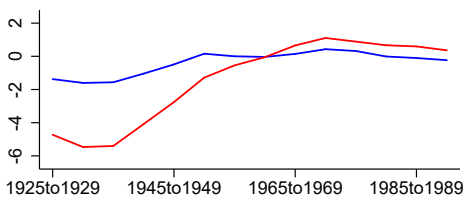

GBR

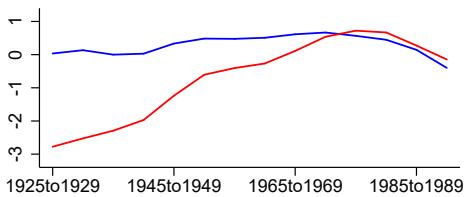

JPN

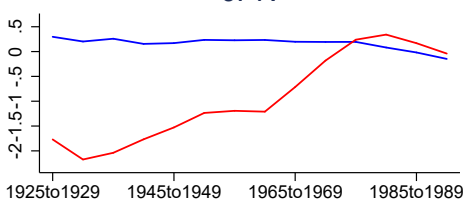

SWE

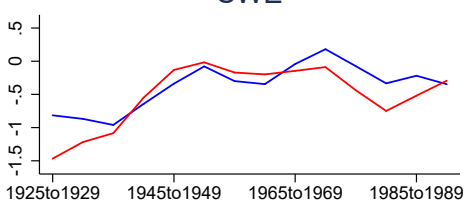


Figure A.3: Actual and Trend LFPR by Country

(Percent)

AUS

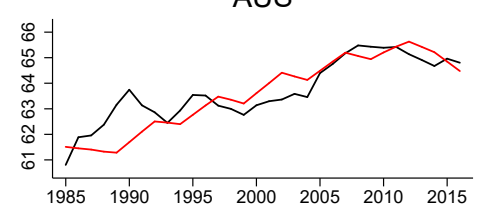

DNK

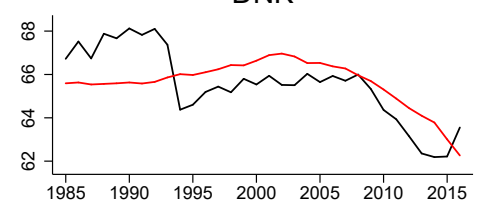

GRC

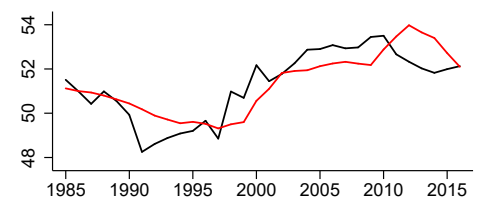

LUX
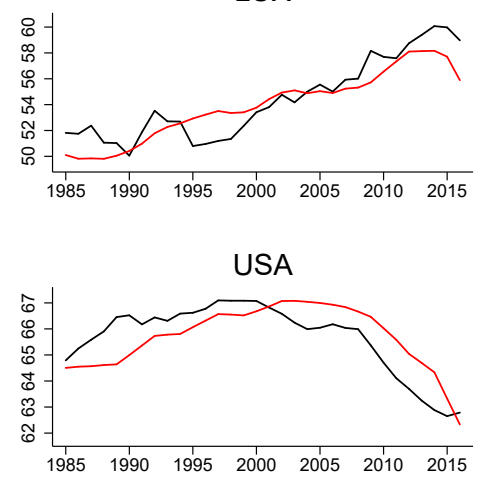

BEL

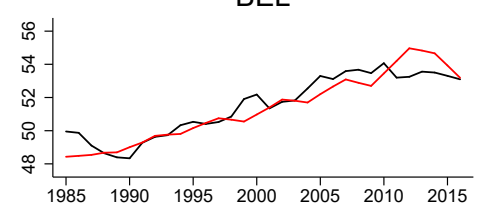

ESP

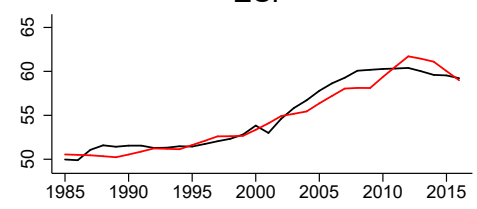

ISR

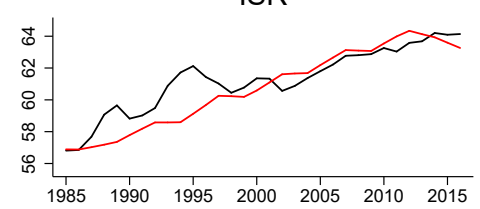

NOR

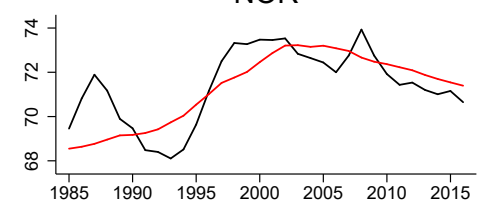

CAN

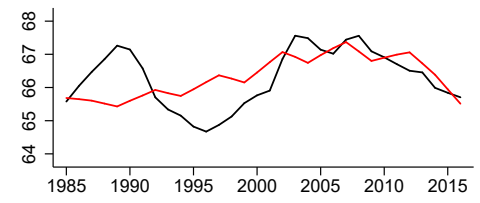

FRA

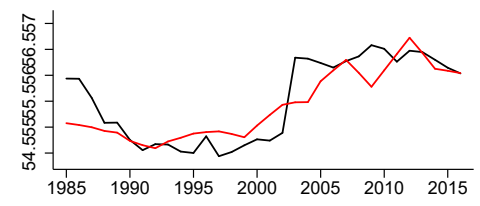

ITA

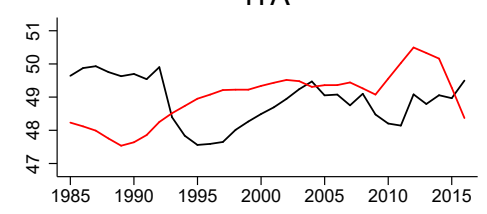

PRT

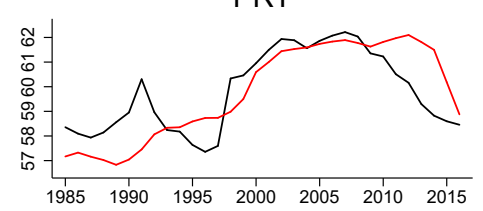

DEU

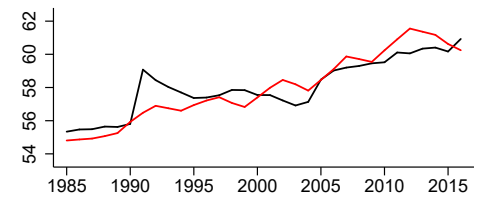

GBR

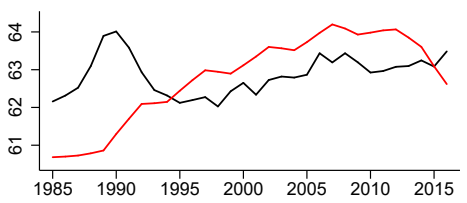

JPN

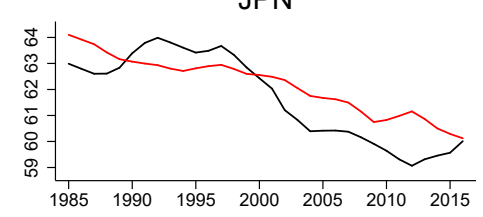

SWE

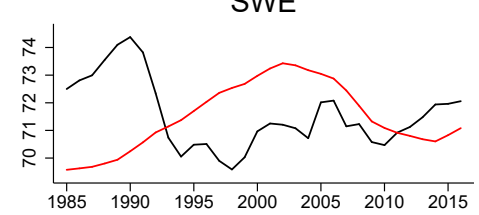

Source: Authors' calculations.

Notes: The black lines denote actual participation rates. The red line denotes the trend participation rates. 
Figure A.4: Trend Projections of LFPR by Country

(Percent)

AUS

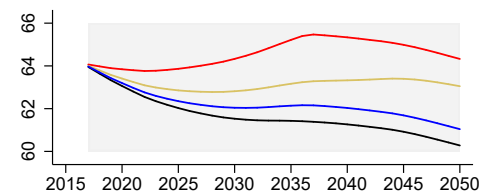

DNK

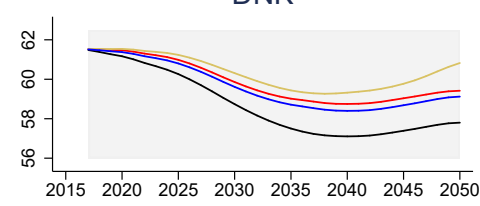

GRC

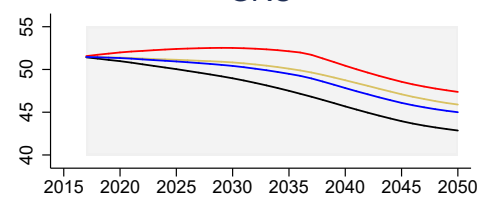

LUX

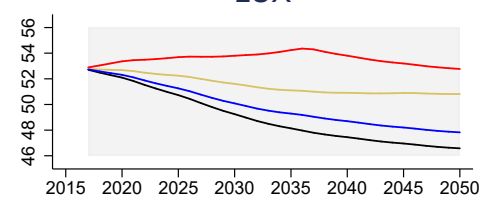

USA

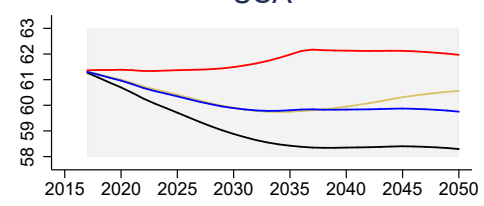

BEL

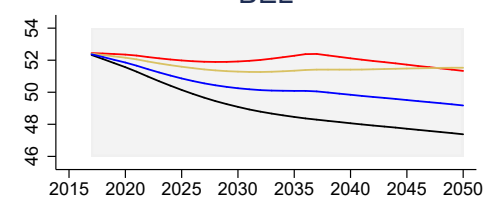

ESP

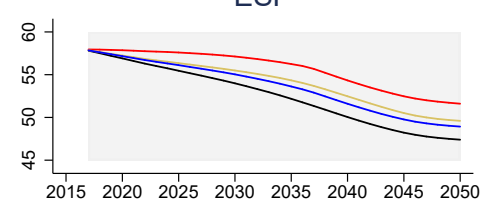

ISR

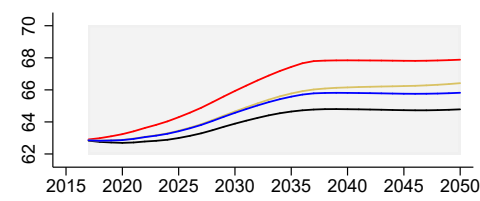

NOR

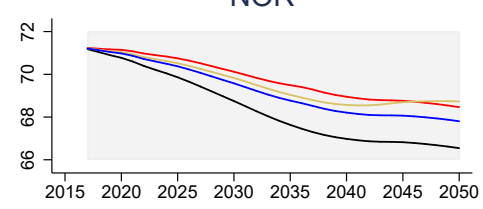

CAN

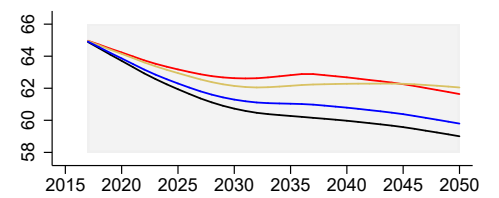

FRA

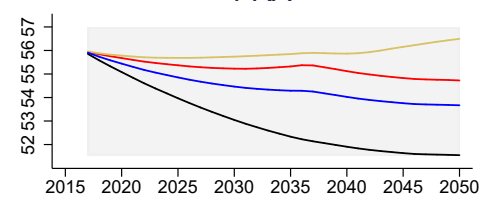

ITA

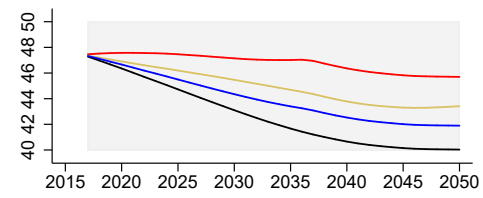

PRT

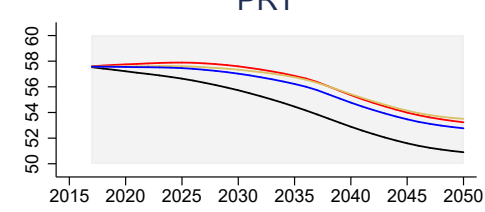

DEU

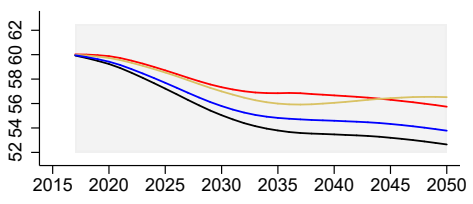

GBR

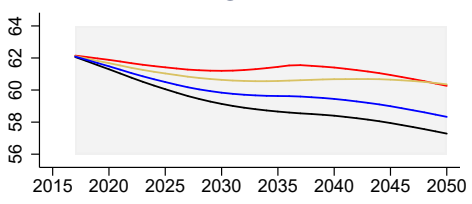

JPN

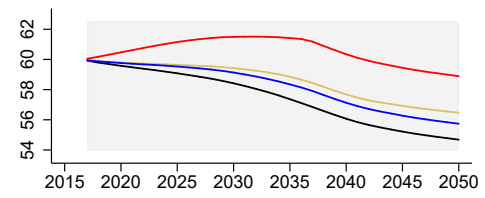

SWE

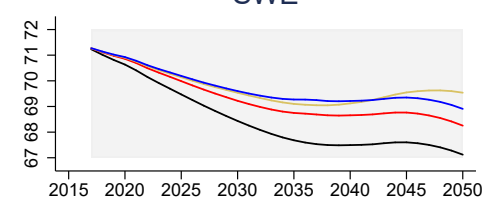

Source: Authors' calculations.

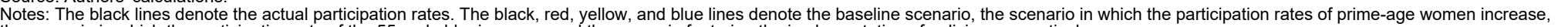
the scenario in which the participation rate of the 55 and older increase, and the scenario featuring the implementation of policies, respectively.

\section{CInternational Monetary Fund. Not for Redistribution}




\section{Appendix B. Calculation of the Cyclical Effects}

Table B.1 reports the results of the estimation of equation (2).

Table B.1: Regressions of Detrended LFPR

\begin{tabular}{|c|c|c|c|}
\hline & $\begin{array}{l}\text { All } \\
(1)\end{array}$ & $\begin{array}{c}\text { Men } \\
(2) \\
\end{array}$ & $\begin{array}{c}\text { Women } \\
(3)\end{array}$ \\
\hline Lag of output gap & $\begin{array}{c}0.055^{* * *} \\
(0.011)\end{array}$ & $\begin{array}{c}0.067^{* * *} \\
(0.011)\end{array}$ & $\begin{array}{c}0.043^{* * *} \\
(0.015)\end{array}$ \\
\hline Observations & 1,010 & 1,010 & 1,010 \\
\hline Countries & 33 & 33 & 33 \\
\hline$R$-squared & 0.155 & 0.151 & 0.120 \\
\hline
\end{tabular}

